\title{
TRANSPARÊNCIA ALÉM DA LEGISLAÇÃO: UMA ANÁLISE DOS PORTAIS ELETRÔNICOS DOS ESTADOS BRASILEIROS COM BASE EM UM INSTRUMENTO DE APOIO À DECISÃO
}

\author{
TRANSPARENCY BEYOND THE LAW: AN ANALYSIS OF THE ELECTRONIC \\ PORTALS OF THE BRAZILIAN STATES BASED ON A DECISION AID TOOL. \\ Maurício Vasconcellos Leão Lyrio ${ }^{1}$ \\ Rogério João Lunkes ${ }^{2}$ \\ Emma Teresa Castello-Taliani ${ }^{3}$
}

1

Doutor em Administração

- com período sanduíche no Departamento de Ciências Econômicas e Empresarias da Universidade de Alcalá (UAH/Espanha) e Mestre em Contabilidade pela Universidade Federal de Santa Catarina (UFSC); Especialista em Gestão Estratégica de Negócios pela Fundação Universidade Regional de Blumenau (FURB); Bacharel em Administração pela Pontifícia Universidade Católica de Minas Gerais (PUC/MG)

Doutor em Engenharia de Produção pela Universidade Federal de Santa Catarina (2003), Pós-Doutorado pela Universidad de ValënciaEspanha (2011), graduação em Ciências Contábeis pela Universidade Federal de Santa Catarina (1996) e mestrado (1999).

3

Doutora em Estudos de Negócios pela Universidade de Valência. Professora de Economia Financeira e Contabilidade da Universidade de Alcalá - Espanha. Membro fundador do PTFE

(Plataforma Tecnológica de Ferrovias Espanhóis) e membro do Conselho Permanente da Comissão de Contabilidade Gerencial da AECA. Há algum tempo, ela desenvolve sua pesquisa focada nas linhas "Sistemas de gestão e custos baseados em atividades" e "Gerenciamento estratégico de custos".
RESUMo: A questão da transparência mediada por computadores é abordada neste estudo, com ênfase na discussão sobre transparência nos portais eletrônicos do poder executivo dos estados brasileiros. Assim, objetiva analisar o nível de transparência desses portais eletrônicos em relação à sua capacidade de disseminação de informações, fomento à cultura de transparência e usabilidade. No que se refere ao enquadramento metodológico, se configura como um estudo de campo descritivo, sendo a coleta de dados realizada por meio de observação direta aos portais dos 26 Estados e do Distrito Federal. Foi utilizado como instrumento de intervenção o Modelo para Avaliação da Transparência da Gestão Pública - ATGP (LYRIO, 2016; LYRIO; LUNKES; TALIANI, 2016). Os resultados apontaram para lacunas ainda a serem preenchidas pelos portais de transparência para que estes consigam fomentar uma cultura de transparência e ajudar na realização das promessas inerentes ao acesso à informação e às políticas de transparência como elementos de uma governança democrática voltada ao cidadão.

PALAVRAS-CHAVE: setor público; avaliação; transparência; Brasil.

ABSTRACT: The issue of computer-mediated transparency is addressed in this study, with emphasis on the discussion on transparency in the electronic portals of executive power in Brazilian states. Thus, it aims to analyze the level of transparency of these electronic portals in relation to its capacity to disseminate information, fostering a culture of transparency and usability. As far as the methodological framework is concerned, it is configured as a descriptive field study, and the data collection is done through direct observation to the portals of the 26 States and the Federal District. The Public Management Transparency Assessment Model - PMTA (Lyrio, 2016; Lyrio, Lunkes, \& Taliani, 2016) was used as an intervention tool. The results pointed to gaps still to be filled by the transparency portals so that they can foster a culture of transparency and help in the fulfillment of the promises inherent in access to information and transparency policies as elements of democratic governance directed towards the citizen.

KEYwORDs: Public Sector; Assessment; Transparency, Brazil. 


\section{INTRODUÇÃO}

O debate sobre transparência no setor público tem aparecido constantemente tanto no meio acadêmico quanto no meio político, administrativo, jornalístico e social. Políticos utilizam-se do termo em discursos, jornalistas debatem o tema, acadêmicos desenvolvem pesquisas para gerar entendimento e ampliar o conhecimento sobre transparência, entidades da sociedade civil o utilizam para falar sobre controle social etc. Geralmente esse debate vem associado a questões como democracia, governança participativa, confiança no governo, governo aberto, corrupção, accountability e controle social (CUCCINIELLO et al., 2014; GRIMMELIKHUIJSEN, 2012; GRIMMELIKHUIJSEN; KASYMOVA, 2015; JORGE; LOURENÇO; ROLAS, 2015; LOURENÇO et al., 2013; MEIJER, 2015; MEIJER; HART; WORTHY, 2015).

Em relação à discussão no meio acadêmico, Cucciniello, Porumbescu e Grimmelikhuijsen (CUCCINIELLO; PORUMBESCU; GRIMMELIKHUIJSEN, 2017) argumentam que houve um tremendo avanço das pesquisas em administração pública com foco na transparência entre os anos 1990 e 2015, sendo que a partir de 2001 inicia um crescimento significativo, que triplica em número de publicações até 2007 e novamente triplica até 2014. Esse avanço nos estudos sobre transparência no setor público foi também evidenciado por Lyrio, Lunkes e Taliani (2018) quando os autores argumentam que a pesquisa sobre o tema vem ganhando força a partir dos anos 2000, de forma alinhada à emergência das teorias de governança pública e à popularização da Internet.

Dentre as diversas questões que envolvem essa discussão no setor público a questão da transparência mediada por computadores - entendida por Meijer (2009) como uma perspectiva modernista de transparência que diz respeito à "[...] habilidade de olhar claramente através das janelas de uma instituição por meio do uso de sistemas computadorizados" (2009, p. 259) - é abordada neste estudo, com ênfase na discussão sobre transparência nos portais eletrônicos do poder executivo dos estados brasileiros.

Acredita-se que para a existência de uma ideia de governança entendida como uma forma de governar baseada em ações conjuntas e coordenadas entre Estado, Mercado e Sociedade Civil para solução dos problemas sociais (KISSLER; HEIDEMANN, 2006; PEDERSEN; SEHESTED; SØRENSEN, 2010; ROBICHAU, 2011; SAUERBRONN, 2017) - é necessário que todas as partes interessadas tenham clareza do que ocorre no âmbito da administração pública, para que possam participar do processo político, cobrar dos governos o atendimento aos seus interesses e responsabilizá-los pelas decisões tomadas.

Torfing, Sørensen e Fotel (2009) argumentam ser necessário o cumprimento de três requisitos para facilitar a contestação pública das narrativas produzidas no âmbito da governança, a saber (i) transparência, (ii) diálogo público e (iii) responsividade. Esses autores chamam 
a atenção para questões importantes no que tange à discussão sobre transparência. A primeira delas diz respeito à visibilidade de informações e decisões dos governos, bem como de seus resultados. A segunda nos remete à abrangência e acessibilidade dessas informações, em um formato que seja de fácil entendimento a todos os públicos e que permita a esses públicos uma participação mais ativa, em um processo democrático. Uma vez que a questão da transparência se faz importante, da mesma forma, se faz importante avaliar o quanto os governos são transparentes e fomentar uma melhoria contínua dessa transparência, com vistas a reforçar a accountability e a democracia. Assim, este estudo tem por objetivo analisar o nível de transparência dos portais eletrônicos do poder executivo dos Estados brasileiros.

No contexto brasileiro, apesar de outros pesquisadores já terem se debruçado sobre a questão da avaliação dos níveis de transparência de entes públicos (ABDALA; TORRES, 2016; CRUZ et al., 2012; RAUPP; PINHO, 2013; SILVA; NASCIMENTO; FERREIRA, 2014; SOUZA et al., 2013; STAROSCKY et al., 2014, 2015) evidenciam-se, ainda, lacunas de conhecimento a serem preenchidas, uma vez que esses estudos recaem geralmente na esfera municipal e procedem com a avaliação baseados na legislação vigente sobre transparência. Assim, este estudo se difere dos estudos anteriores pelo fato de que se baseia não somente da legislação sobre transparência existente no Brasil, bem como aborda uma esfera de governo ainda não explorada exaustivamente, contribuindo para o avanço do conhecimento no sentido de ampliar o escopo sobre avaliação de transparência no âmbito brasileiro.

Por incorporar na avaliação elementos que vão além dos considerados na legislação brasileira, pode-se trazer à discussão outras questões importantes no que tange à transparência governamental em meio eletrônico. Essas questões podem servir de sugestões de caminhos e práticas de transparência a serem utilizadas no âmbito nacional. Assim, os praticantes - servidores públicos que lidam com o desenvolvimento e manutenção de portais de transparência no Brasil - podem se valer dos resultados deste estudo para aprimorar os portais de transparência brasileiros, incorporando elementos que porventura não estejam sendo considerados atualmente.

Após essa seção introdutória o artigo apresenta em sua seção 2 uma breve discussão sobre avaliação de transparência no âmbito do setor público; em seguida, na seção 3, apresenta o enquadramento metodológico, o modelo de avaliação utilizado e os procedimentos para coleta e análise dos dados. A seção 4 apresenta e analisa os resultados do estudo e; finalmente, na seção 5 tece algumas considerações finais sobre o estudo.

\section{AVALIAÇÃO DE TRANSPARÊNCIA NO SETOR PÚBLICO}

Avaliar transparência dos entes do setor público se constitui em uma iniciativa de pesquisa que objetiva entender o fenômeno da transparência a partir da perspectiva do que é disponibilizado à socie- 


\section{Revista de Gestão Pública}

dade, bem como o que é considerado no processo de avaliação dos níveis de transparência desses entes. Essa seção busca revisitar alguns desses trabalhos, realizados nos últimos 5 anos, com vistas a apresentar um panorama da pesquisa sobre o tema. Vale salientar que a seção não objetiva ser exaustiva no que tange aos estudos considerados, por outro lado, visa exemplificar alguns desses trabalhos, considerando seus objetivos, os métodos empregados e os resultados alcançados a fim de justificar o desenvolvimento deste estudo, conforme apresentado no Quadro 1.

QUADRO 1: Pesquisas anteriores sobre avaliação de transparência no setor público

\begin{tabular}{|c|c|c|c|}
\hline Autor / ano & Objetivo & Instrumento de intervenção & Resultados \\
\hline (CRUZ et al., 2012) & $\begin{array}{l}\text { Verificar os níveis de transparência das } \\
\text { informações relativas à gestão pública nos } \\
\text { portais eletrônicos de } 96 \text { municípios incluídos } \\
\text { como os } 100 \text { mais populosos do Brasil e } \\
\text { identificar as características e indicadores } \\
\text { sócio-econômicos que podem contribuir } \\
\text { para a explicação dos níveis de transparência } \\
\text { observados. }\end{array}$ & $\begin{array}{l}\text { Índice de transparência da gestão } \\
\text { pública municipal, construído a partir } \\
\text { do Índice de transparência de los } \\
\text { ayuntamientos (ITA) desenvolvido } \\
\text { pelo comitê espanhol da Transparency } \\
\text { International. }\end{array}$ & $\begin{array}{l}\text { Os índices de transparência alcançados } \\
\text { pelos municípios analisados foram } \\
\text { considerados baixos e incompatíveis com } \\
\text { seu desenvolvimento sócio-econômico. }\end{array}$ \\
\hline $\begin{array}{l}\text { (BONSÓN et al., } \\
\text { 2012) }\end{array}$ & $\begin{array}{l}\text { Fornecer uma visão geral sobre o uso de web } \\
2.0 \text { e mídias sociais com vistas a determinar se } \\
\text { os governos locais da EU estão utilizando essas } \\
\text { tecnologias para aumento da transparência e } \\
\text { e-participação. }\end{array}$ & $\begin{array}{l}\text { Análise de regressão considerando } \\
\text { considerando a presença de } 8 \text { itens nas } \\
\text { páginas oficiais dos governos locais } \\
\text { e presença nas plataformas Twitter, } \\
\text { Facebook, LinkedIn, You Tube e Google } \\
\text { blogs. }\end{array}$ & $\begin{array}{l}\text { Os resultados mostraram alto grau } \\
\text { de heterogeneidade no uso de web } \\
2.0 \text { e ferramentas de mídia social. A } \\
\text { maioria dos governos analisados utiliza } \\
\text { essas ferramentas para o aumento da } \\
\text { transparência, por outro lado, ainda não } \\
\text { estão amadurecidos no que tange ao uso } \\
\text { dessas ferramentas para reforçar o diálogo } \\
\text { corporativo e a e-participacão. }\end{array}$ \\
\hline $\begin{array}{l}\text { (SOUZA et al., } \\
\text { 2013) }\end{array}$ & $\begin{array}{l}\text { Analisar a transparência dos municípios mais } \\
\text { populosos do Rio Grande do Norte. }\end{array}$ & $\begin{array}{l}\text { Metodologia proposta por Biderman e } \\
\text { Puttomatti para estabelecer um ranking } \\
\text { para o nível de transparência dos } \\
\text { municípios analisados. }\end{array}$ & $\begin{array}{l}\text { Os resultados mostraram que os municípios } \\
\text { ainda precisam melhorar seus níveis de } \\
\text { transparência para melhorar o contato com a } \\
\text { população e permitir o exercício do controle } \\
\text { social. Verificou-se associação entre os níveis } \\
\text { de transparência e o Ideb do } 5^{0} \text { ao } 9^{\circ} \text { ano e } \\
\text { IDH. }\end{array}$ \\
\hline $\begin{array}{l}\text { (CÁZARES; } \\
\text { CEJUDO, 2013) }\end{array}$ & $\begin{array}{l}\text { Analisar o funcionamento dos sistemas de } \\
\text { acesso à informação pública em quatro países } \\
\text { centroamericanos (Guatemala, Honduras, } \\
\text { Nicarágua e Panamá). }\end{array}$ & $\begin{array}{l}\text { Metodologia utilizada no projeto } \\
\text { Métrica de la Transparencia 2010, } \\
\text { desenvolvido pelo Centro de Investigación } \\
\text { y Docencia Económicas (CIDE). }\end{array}$ & $\begin{array}{l}\text { Os resultados apontaram para avanços } \\
\text { no reconhecimento do direito de acesso à } \\
\text { informação, principalmente em relação à } \\
\text { normatividade e institucionalidade. Por } \\
\text { outro lado, os autores concluem que ainda } \\
\text { existe um longo caminho a percorrer para } \\
\text { a consolidação de uma política de acesso à } \\
\text { informação pública. }\end{array}$ \\
\hline
\end{tabular}




\section{Revista de Gestão Pública}

\begin{tabular}{|c|c|c|c|}
\hline $\begin{array}{l}\text { (LOURENÇO et } \\
\text { al., 2013) }\end{array}$ & $\begin{array}{l}\text { Propor um modelo para avaliar como as } \\
\text { entidades do setor público estão aproveitando } \\
\text { a Internet como ferramenta para divulgação } \\
\text { de informações e promoção da transparência, } \\
\text { principalmente em relação ao uso de recursos } \\
\text { públicos e demonstrar a aplicabilidade do } \\
\text { modelo avaliando dois municípios (em Portugal } \\
\text { e Itália). }\end{array}$ & $\begin{array}{l}\text { Modelo próprio que calcula o índice de } \\
\text { transparência considerando visibilidade, } \\
\text { formato e modo de entrega das } \\
\text { informações. }\end{array}$ & $\begin{array}{l}\text { Os resultados sugerem que, a despeito das } \\
\text { exigências internacionais e da legislação } \\
\text { em matéria de transparência os municípios } \\
\text { analisados ainda não revelaram informaçõ̃es } \\
\text { importantes para o processo de prestação de } \\
\text { contas, bem como os dados disponíveis não } \\
\text { possuem visibilidade e formato adequado } \\
\text { para facilitar o processamento e análise } \\
\text { pelas partes interessadas na perspectiva do } \\
\text { governo aberto. }\end{array}$ \\
\hline $\begin{array}{l}\text { (RAUPP; PINHO, } \\
\text { 2013) }\end{array}$ & $\begin{array}{l}\text { Comparar os portais eletrônicos das câmaras } \\
\text { municipais dos Estados da Bahia e de Santa } \\
\text { Catarina para observar o fenômeno da prestação } \\
\text { de contas para construção de condições para } \\
\text { accountability }\end{array}$ & $\begin{array}{l}\text { Modelo de análise proposto por Raupp } \\
\text { (2011) com dados coletados por meio de } \\
\text { protocolo de observação. }\end{array}$ & $\begin{array}{l}\text { Os resultados evidenciaram que, de maneira } \\
\text { geral, não há prestação de contas nos portais } \\
\text { eletrônicos dos legislativos locais dos } \\
\text { municípios analisados. }\end{array}$ \\
\hline $\begin{array}{l}\text { (SILVA; } \\
\text { NASCIMENTO; } \\
\text { FERREIRA, 2014) }\end{array}$ & $\begin{array}{l}\text { Verificar o cumprimento dos dispositivos da } \\
\text { Lei de Responsabilidade Fiscal referentes à } \\
\text { transparência da prestação de contas da gestão } \\
\text { pública via Internet em todos os municípios } \\
\text { goianos. }\end{array}$ & $\begin{array}{l}\text { Estatística descritiva considerando o } \\
\text { cumprimento dos requisitos da LRF. }\end{array}$ & $\begin{array}{l}\text { Os resultados apontaram que o Estado do } \\
\text { Goiás atende parcialmente aos requisitos } \\
\text { da LRF, tendo em vista que nem todos os } \\
\text { municípios cumprem totalmente a legislação } \\
\text { vigente. }\end{array}$ \\
\hline $\begin{array}{l}\text { (STAROSCKY et } \\
\text { al., 2014) }\end{array}$ & $\begin{array}{l}\text { Avaliar o nível de transparência dos portais dos } \\
\text { municípios que fazem parte da Secretaria de } \\
\text { Desenvolvimento Regional - SDR - de Chapecó, } \\
\text { no Estado de Santa Catarina / Brasil. }\end{array}$ & $\begin{array}{l}\text { Modelo proposto por Nunes (2013), } \\
\text { desenvolvido com base na Metodologia } \\
\text { Multicritério de Apoio à Decisão } \\
\text { - Construtivista, considerando a } \\
\text { legislação brasileira sobre transparência. }\end{array}$ & $\begin{array}{l}\text { Os resultados da pesquisa mostraram que } \\
\text { os portais municipais ainda estão aquém } \\
\text { do desejado, em termos de transparência } \\
\text { pública, considerando os requisitos } \\
\text { existentes na legislação brasileira. }\end{array}$ \\
\hline $\begin{array}{l}\text { (CUCCINIELLO } \\
\text { et al., 2014) }\end{array}$ & $\begin{array}{l}\text { Avaliar se as informações consideradas mais } \\
\text { relevantes pela população para interação com as } \\
\text { autoridades são atualmente disponibilizadas. }\end{array}$ & $\begin{array}{l}\text { Survey envolvendo pessoas entre } \\
18 \text { e } 65 \text { anos que vivem nas capitais } \\
\text { provinciais da Itália. }\end{array}$ & $\begin{array}{l}\text { Os resultados mostraram que as capitais } \\
\text { provinciais italianas não divulgam as } \\
\text { informações consideradas mais relevantes } \\
\text { pela população, sendo que as informações } \\
\text { divulgadas são as que as capitais são } \\
\text { obrigadas a divulgar a fim de cumprir os } \\
\text { regulamentos de transparência. }\end{array}$ \\
\hline (CRUZ et al., 2015) & $\begin{array}{l}\text { Desenvolver um Índice de Transparência } \\
\text { Municipal baseado em um método participativo } \\
\text { para identificar as dimensões e indicadores de } \\
\text { transparência. }\end{array}$ & $\begin{array}{l}\text { Modelo próprio desenvolvido a } \\
\text { partir de interações com especialistas } \\
\text { e representantes de instituições } \\
\text { governamentais e de controle, com base } \\
\text { em um método multicritério de análise } \\
\text { de decisão. }\end{array}$ & $\begin{array}{l}\text { A análise realizada em } 308 \text { municípios } \\
\text { de Portugal apontou que as práticas } \\
\text { de transparência ainda estão pouco } \\
\text { desenvolvidas no contexto dos governos } \\
\text { locais portugueses. Em relação à } \\
\text { metodologia, os autores chamam a atenção } \\
\text { para o fato de que o modelo proposto leva } \\
\text { em consideração a importância relativa de } \\
\text { cada critério de avaliação, alegando que não } \\
\text { é correto dar a mesma importância a cada } \\
\text { um deles. }\end{array}$ \\
\hline
\end{tabular}




\section{Revista de Gestão Pública}

\begin{tabular}{|c|c|c|c|}
\hline (DINIZ, 2015) & $\begin{array}{l}\text { Avaliar os websites de municípios cearenses } \\
\text { em relação ao nível de transparência digital } \\
\text { considerando as informações e serviços } \\
\text { disponibilizados nos portais. }\end{array}$ & $\begin{array}{l}\text { A pesquisa foi conduzida por } \\
\text { meio de um roteiro de navegação } \\
\text { orientada organizado em } 3 \text { dimensões: } \\
\text { informaçóes gerais, informações e } \\
\text { serviços técnicos, informaçoes e serviços } \\
\text { específicos. }\end{array}$ & $\begin{array}{l}\text { Os resultados sugerem que a maioria dos } \\
\text { municípios analisados desenvolveu portais } \\
\text { eletrônicos com a intenção de apenas atender } \\
\text { às exigências normativas. Além disso, os } \\
\text { resultados mostraram que os municípios } \\
\text { com maior número de habitantes e mais } \\
\text { recursos tendem a ser mais criteriosos na } \\
\text { oferta de informações e serviços para além } \\
\text { do cumprimento das exigênias legais. }\end{array}$ \\
\hline $\begin{array}{l}\text { (MEIJER; HART; } \\
\text { WORTHY, 2015) }\end{array}$ & $\begin{array}{l}\text { Prover um quadro interpretativo para guiar } \\
\text { e estruturar avaliações de transparência } \\
\text { governamental. }\end{array}$ & $\begin{array}{l}\text { Quadro teórico envolvendo } \\
\text { transparência política e administrativa. }\end{array}$ & $\begin{array}{l}\text { Os autores argumentam que o quadro de } \\
\text { análise proposto pode contribuir para o } \\
\text { avanço da discussão sobre avaliação de } \\
\text { transparência no sentido de debater os níveis } \\
\text { de transparência requeridos e estabelecer as } \\
\text { necessidades de transparência em contextos } \\
\text { específicos. }\end{array}$ \\
\hline $\begin{array}{l}\text { (STAROSCKY et } \\
\text { al., 2015) }\end{array}$ & $\begin{array}{l}\text { Avaliar os níveis de transparência apresentados } \\
\text { nos portais eletrônicos de municípios que } \\
\text { compõem a Seretaria de Desenvolvimento } \\
\text { Regional de Joinville - SC. }\end{array}$ & $\begin{array}{l}\text { Modelo proposto por Nunes (2013), } \\
\text { desenvolvido com base na Metodologia } \\
\text { Multicritério de Apoio à Decisão } \\
\text { - Construtivista, considerando a } \\
\text { legislação brasileira sobre transparência. }\end{array}$ & $\begin{array}{l}\text { Os resultados mostraram que ainda } \\
\text { não existe uma cultura de transparência } \\
\text { internalizada nos municípios analisados, } \\
\text { tendo em vista que } 50 \% \text { deles ainda não } \\
\text { atendem às exigências da legislação } \\
\text { brasileira sobre transparência. }\end{array}$ \\
\hline $\begin{array}{l}\text { (ABDALA; } \\
\text { TORRES, 2016) }\end{array}$ & $\begin{array}{l}\text { Avaliar os portais de transparência de } 5 \text { Estados } \\
\text { brasileiros (1 por região), para verificar a } \\
\text { funcionalidade destes como fonte de acesso à } \\
\text { informação e fortalecimento da participação e } \\
\text { controle social. }\end{array}$ & $\begin{array}{l}\text { "Escala avaliativa desenvolvida } \\
\text { por Sales (2012) com o objetivo de } \\
\text { verificar se os portais de transparência } \\
\text { dos estados se apresentam como } \\
\text { instrumentos efetivos para o exercício } \\
\text { do controle da atividade pública." (p. } \\
\text { 150) }\end{array}$ & $\begin{array}{l}\text { Os portais estudados apresentaram } \\
\text { problemas de falta de informação ou } \\
\text { insuficiência, demonstrando que ainda existe } \\
\text { um longo caminho até que esses portais } \\
\text { realmente se tornem espaços digitais para o } \\
\text { exercício da cidadania, tanto em termos de } \\
\text { participação quanto de controle e pressão } \\
\text { sobre os governos. }\end{array}$ \\
\hline $\begin{array}{l}\text { (GAMA; } \\
\text { RODRIGUES, } \\
\text { 2016) }\end{array}$ & $\begin{array}{l}\text { Verificar o comportamento da demanda por } \\
\text { informações contábeis nas universidades } \\
\text { públicas federais brasileiras após a edição da Lei } \\
\text { de Acesso à Informação. }\end{array}$ & $\begin{array}{l}\text { O estudo foi conduzido por meio de um } \\
\text { levantamento de informações do portal } \\
\text { do e-sic, nos itens relatórios estatísticos } \\
\text { e download de dados disponível no site. }\end{array}$ & $\begin{array}{l}\text { Os resultados apontam para o fato de que } \\
\text { as universidades brasileiras ainda não se } \\
\text { ajustaram ao que preconiza a LAI, que a } \\
\text { existência de instrumentos que obrigam } \\
\text { a transparência ativa não são garantia de } \\
\text { sua implementação em curto prazo e que o } \\
\text { grande número de demanda por informação } \\
\text { parece refletir o entusiasmo da sociedade } \\
\text { para com o desenvolvimento de uma política } \\
\text { mais clara de direito à informação no Brasil. }\end{array}$ \\
\hline
\end{tabular}

FONTE: Elaborado pelos autores 
A partir da análise do Quadro I é possível encontrar algumas similaridades na pesquisa sobre avaliação de transparência no setor público. Em primeiro lugar, a pesquisa aponta para uma ênfase na análise de transparência em nível municipal, apenas 4 estudos não abordaram esse nível de governo. Cázares e Cejudo (2013) discutiram a questão em nível nacional, Meijer et al. (2015) não definiram uma esfera de governo no quadro de análise que propuseram e Gama e Rodrigues (2016) abordaram a questão nas universidades públicas brasileiras. $\mathrm{O}$ único estudo realizado em nível de Estado foi o de Abdala e Torres (2016), porém, adotando apenas uma amostra de 5 Estados distribuídos entre as regiões do Brasil.

Em segundo lugar, os estudos apontam para o uso de métodos quantitativos de pesquisa, adotando diversas formas de modelagem para cálculo de índices de transparência e, em sua maioria, analisando a transparência ativa, ou seja, as informações disponibilizadas de forma sistemática em meio eletrônico pelos entes analisados. Exceção pode ser feita em relação ao trabalho desenvolvido por Cucciniello et al. (2014), que buscou ter em conta a perspectiva da população em relação ao que deve ser considerado na avaliação da transparência em entes públicos.

Por último, mas não menos importante, os estudos demonstram que ainda existem lacunas a serem preenchidas no que se refere ao avanço da transparência pública na Internet e ao desenvolvimento de uma cultura de transparência no âmbito dos entes analisados. Além disso, percebe-se ainda forte viés legalista nos estudos, uma vez que em grande parte tratam o tema a partir do atendimento à legislação sobre transparência existente nos contextos analisados.

Este artigo dá prosseguimento a essas pesquisas, se diferenciando pelo fato de que busca analisar uma esfera de governo ainda pouco discutida, a saber, nível intermediário de governo (Estados brasileiros), bem como busca ter em conta outras questões que vão além dos requisitos legais no processo de avaliação. Por outro lado, se alinha aos estudos desenvolvidos por Staroscky et al. (2014, 2015) e Cruz et al. (2015) pelo fato de adotarem modelos multicritério de análise de decisão.

\section{METODOLOGIA}

No que se refere ao enquadramento metodológico, o estudo se configura como um estudo de campo descritivo, sendo a coleta de dados realizada por meio de observação direta. Se configura como um estudo de campo pois analisa simultaneamente todos os estados brasileiros, enquanto se configura como descritiva pelo fato de que visa descrever os níveis de transparência dos entes analisados sem se aprofundar nos motivos que levam um Estado a ser mais ou menos transparente.

No que se refere à coleta de dados, as informações sobre a transparência da gestão pública governamental serão obtidas junto aos portais da transparência dos governos analisados (Quadro 2), por meio de observação direta pois, “[...] baseado nos objetivos da pesquisa e num 
Revista de Gestão Pública

roteiro de observação, o pesquisador procura ver e registrar o máximo de ocorrências que interessam ao seu trabalho" (GODOY, 2006, p. 133). Os dados foram coletados no período correspondente a Dezembro de 2015 a Janeiro de 2016, e representam os níveis de transparência alcançados no momento da avaliação.

QUADRO 2: Portais de transparência utilizados no estudo

\begin{tabular}{|c|c|c|c|}
\hline Estado & Link & Estado & Link \\
\hline Acre & $\begin{array}{l}\text { http://www.sefaznet.ac.gov.br/ } \\
\text { transparencia/servlet/portaltransparencia }\end{array}$ & Paraíba & http://transparencia.pb.gov.br// \\
\hline Alagoas & http://www.transparencia.al.gov.br/ & Paraná & http://www.portaldatransparencia.pr.gov.br/ \\
\hline Amapá & http://www.transparencia.ap.gov.br/ & Pernambuco & $\begin{array}{l}\text { http://www2.transparencia.pe.gov.br/web/portal-da- } \\
\text { transparencia }\end{array}$ \\
\hline Amazonas & $\begin{array}{l}\text { http://www.transparencia.am.gov.br/ } \\
\text { transpprd/ }\end{array}$ & Piauí & http://transparencia.pi.gov.br/ \\
\hline Bahia & http://www.transparencia.ba.gov.br/ & Rio de Janeiro & http://www.transparencia.rj.gov.br/ \\
\hline Ceará & http://www.transparencia.ce.gov.br/ & $\begin{array}{l}\text { Rio Grande do } \\
\text { Norte }\end{array}$ & http://www.transparencia.rn.gov.br/ \\
\hline $\begin{array}{l}\text { Distrito } \\
\text { Federal }\end{array}$ & $\begin{array}{l}\text { http://www.transparencia.df.gov.br/Pages/ } \\
\text { inicio.aspx }\end{array}$ & Rio Grande do Sul & $\begin{array}{l}\text { http://www.transparencia.rs.gov.br/webpart/system/ } \\
\text { PaginaInicial.aspx }\end{array}$ \\
\hline $\begin{array}{l}\text { Espírito } \\
\text { Santo }\end{array}$ & http://www.portaldatransparencia.es.gov.br/ & Rondônia & http://www.transparencia.ro.gov.br/ \\
\hline Goiás & http://www.transparencia.go.gov.br/ & Roraima & http://www.transparencia.rr.gov.br/ \\
\hline Maranhão & http://www.transparencia.ma.gov.br/ & Santa Catarina & http://www.sef.sc.gov.br/transparencia \\
\hline $\begin{array}{c}\text { Mato } \\
\text { Grosso } \\
\end{array}$ & http://www.transparencia.mt.gov.br/ & São Paulo & http://www.transparencia.sp.gov.br/ \\
\hline $\begin{array}{c}\text { Mato } \\
\text { Grosso do } \\
\text { Sul } \\
\end{array}$ & $\begin{array}{l}\text { http://www.portaldatransparencia.ms.gov. } \\
\mathrm{br} /\end{array}$ & Sergipe & http://www.transparenciasergipe.se.gov.br/setp/index.html \\
\hline $\begin{array}{l}\text { Minas } \\
\text { Gerais }\end{array}$ & http://www.transparencia.mg.gov.br/ & Tocantins & http://www.transparencia.to.gov.br/ \\
\hline
\end{tabular}

FONTE: Elaborado pelos autores

Finalmente, em relação ao instrumento de intervenção adotado, foi utilizado o Modelo de Avaliação da Transparência da Gestão Pública - ATGP (LYRIO, 2016; LYRIO; LUNKES; TALIANI, 2016), construído por meio da aplicação da Metodologia Multicritério de Apoio à Decisão - Construtivista (ENSSLIN; MONTBELLER-NETO; NORONHA, 2001). O modelo utiliza- 
do foi construído com base na literatura especializada sobre transparência, na legislação sobre transparência existente no âmbito do Brasil e da Espanha, no Índice de Transparência das Comunidades Autônomas Espanholas (INCAU) e no modelo proposto por Nunes (2013). Assim, incorpora na avaliação questões que extrapolam o âmbito legal, considerando questões ligadas ao fomento à cultura de transparência, a informações relativas ao desempenho dos serviços públicos, uso de dados abertos e mídias sociais, entre outras questões. Seu processo de validação foi realizado junto a um painel composto por especialistas em transparência, que validaram cada etapa de sua construção, bem como os descritores propostos. Além disso, esses especialistas foram responsáveis pela ponderação dos critérios de avaliação.

O modelo ATGP é organizado em 3 áreas de preocupação, a saber: (i) conteúdo informacional; (ii) fomento à cultura de transparência, e; (iii) usabilidade dos portais. Essas áreas de preocupação são desdobradas em 71 descritores utilizados para analisar questões específicas sobre transparência nos portais eletrônicos dos governos estaduais do Brasil. Cada um dos critérios de avaliação possui uma importância relativa e dois níveis de referência (Bom e Neutro), o que permite a agregação da avaliação em cada critério em um critério de síntese, conforme sugerido por Bana-e-Costa e Vansnick (1997).

A Figura 1 apresenta como exemplo o descritor utilizado para verificar a disponibilização de informações sobre os programas de governo. A escala ordinal descreve quais as informações o portal deve disponibilizar para atender a cada um dos níveis de impacto do descritor.

FIGURA 1 - Descritor utilizado para avaliar a disponibilização de informações sobre os programas de governo

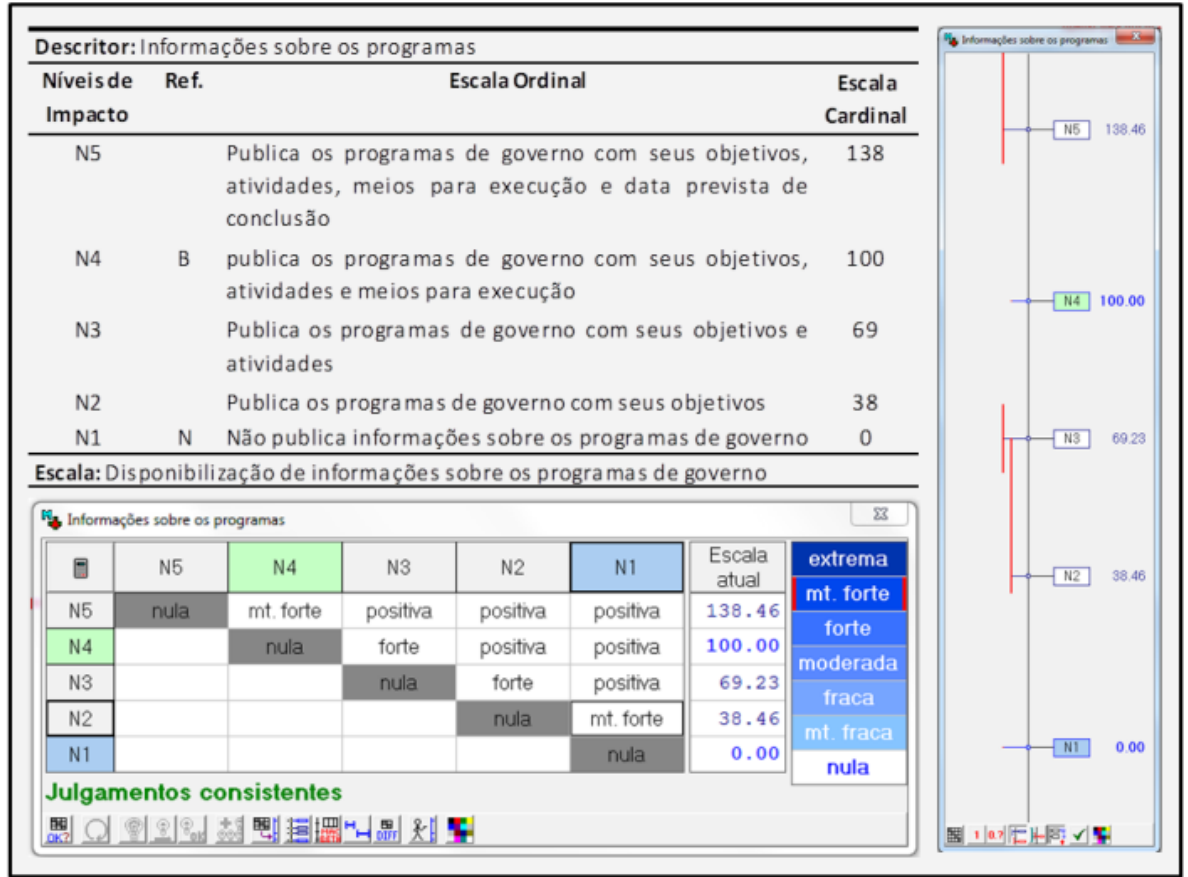

FONTE: Lyrio, 2016. 
A escala cardinal, por sua vez, é construída utilizando-se o software M-Macbeth (BANA-E-COSTA; CORTE; VANSNICK, 2005), que analisa de forma semântica, em uma comparação par-a-par, a perda de atratividade percebida na passagem de um nível de impacto para outro imediatamente inferior. Uma vez que aos níveis de ancoragem Bom e Neutro são atribuídos sempre 100 e o pontos respectivamente, é possível agregar o resultado da avaliação em cada um dos indicadores por meio de um critério único de síntese.

\section{APRESENTAÇÃO E ANÁLISE DOS RESULTADOS}

A presente seção busca inicialmente apresentar a estrutura administrativa do Estado Brasileiro para, em seguida, adentrar na análise dos níveis de transparência de seus portais de Transparência.

\section{ESTRUTURA ADMINISTRATIVA DO ESTADO BRASILEIRO}

A ditadura militar no Brasil teve início em 1964, com o golpe de Estado, findando em 1985 com o início da Sexta República Brasileira, também conhecida como Nova República. Após o fim da ditadura, houve um período de transição com a instituição de uma constituinte que findou em 1988 com a promulgação da Nova Constituição, atualmente em vigor. A Nova Constituição estabeleceu o Brasil como uma República Federativa Presidencialista, bem como garantiu o direito aos cidadãos de viver em uma democracia representativa e estabeleceu os princípios fundamentais de um Estado Democrático de Direito. Em seus artigos $1^{0}$ a $4^{\underline{0}}$ a Nova Constituição (BRASIL, 1988) trata desses princípios, estabelecendo os fundamentos para a existência do Estado, a divisão estatal em três poderes (executivo, legislativo e judiciário), os objetivos da nação e os princípios para as relações internacionais.

Em seu artigo $18^{\circ}$ a Nova Constituição estabelece a organização político-administrativa da República, desdobrada em União, Estados, Distrito Federal e Municípios e em seu Capítulo III estabelece suas competências e estrutura. Atualmente o Brasil é composto por 26 Estados - Acre, Alagoas, Amazonas, Amapá, Bahia, Ceará, Espírito Santo, Goiás, Maranhão, Mato Grosso, Mato Grosso do Sul, Minas Gerais, Pará, Paraíba, Paraná, Pernambuco, Piauí, Rio de Janeiro, Rio Grande do Norte, Rio Grande do Sul, Rondônia, Roraima, Santa Catarina, São Paulo, Sergipe e Tocantins - e o Distrito Federal.

\section{ANÁLISE DO NÍVEL DE TRANSPARÊNCIA DOS PORTAIS ELETRÔNICOS ESTADUAIS}

Iniciando-se a análise dos portais de transparência dos Estados brasileiros, apresenta-se a Figura 2, a qual apresenta um perfil de desempenho com a média alcançada pelos Estados em termos de nível global de transparência. Essa figura apresenta o modelo proposto, com suas áreas de preocupação desdobradas em 꾸ำ nível das preocupações. 
Em uma avaliação global os Estados brasileiros apresentaram uma média de transparência de 8 pontos, que apesar de se encontrar em nível adequado, é considerado baixo e abre uma ressalva em relação às práticas de transparência adotadas pelos Estados. O destaque positivo diz respeito à área de preocupação Usabilidade do portal que alcançou uma média geral de 35 pontos. Além disso, essa área de preocupação é também a que apresenta o menor desvio-padrão (15 pontos), evidenciando certa homogeneidade de práticas em relação a essa questão.

Em seguida destaca-se a questão do Conteúdo informacional. Nessa área de preocupação os Estados brasileiros alcançaram uma média geral de 1o pontos, adequada, porém baixa. Também nessa área de preocupação, o desvio-padrão de 17 pontos dá a entender que existem práticas homogêneas em relação ao fornecimento de informações no âmbito dos Estados analisados.

FIGURA 2 - Perfil de desempenho com o nível médio de transparência alcançado pelos Estados brasileiros
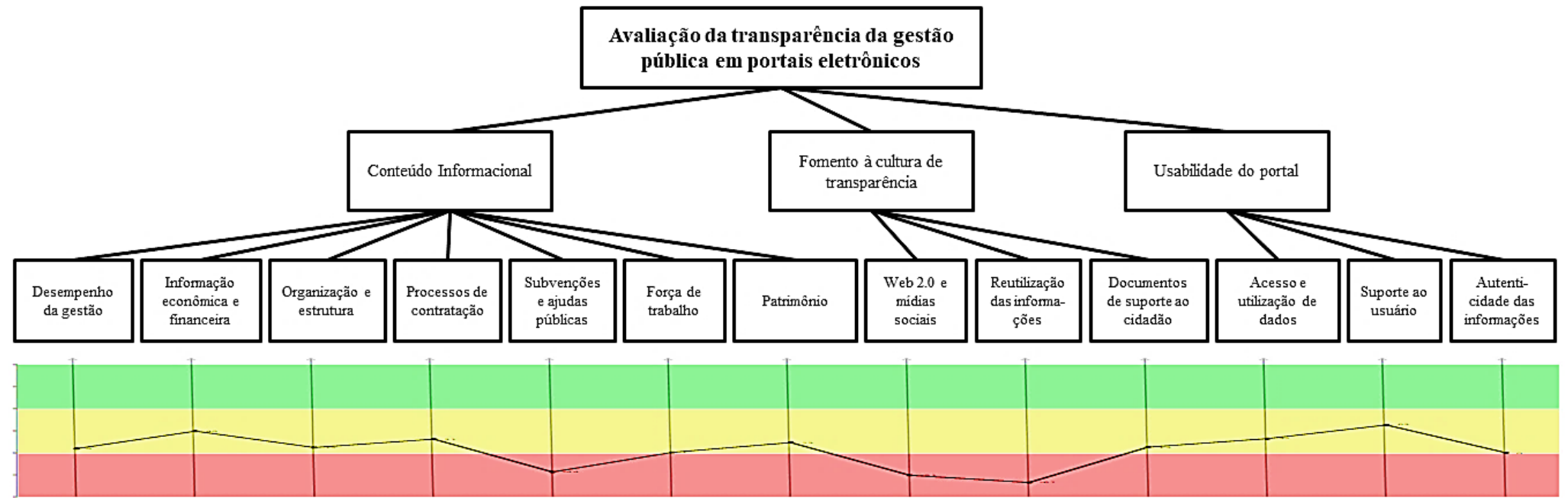

FONTE: Dados da pesquisa

O ponto crítico no que tange à avaliação dos portais de transparência brasileiros diz respeito ao Fomento à cultura de transparência. Nessa área de preocupação evidenciou-se uma pontuação média negativa de 42 pontos, configurando-se como comprometedora. A análise deixa evidente que os Estados brasileiros não estão se preocupando em utilizar os portais de transparência como um instrumento de fortalecimento da cultura de transparência bem como não se preocupam em utilizar esses portais como um canal de aproximação do governo com a sociedade. Além disso, essa área de preocupação 
apresentou um desvio-padrão de 32 pontos, o que evidencia disparidade de práticas por parte dos Estados no que tange a essa questão.

A Figura 3 apresenta o resultado global da avaliação por Estado. São Paulo é o Estado que alcançou melhor pontuação na avaliação (40 pontos), se constituindo em um benchmarking a ser seguido pelo demais Estados.

$$
\begin{aligned}
& \text { FIGURA } 3 \text { - Ranking global de transparência por Estado } \\
& 50 \quad 40
\end{aligned}
$$

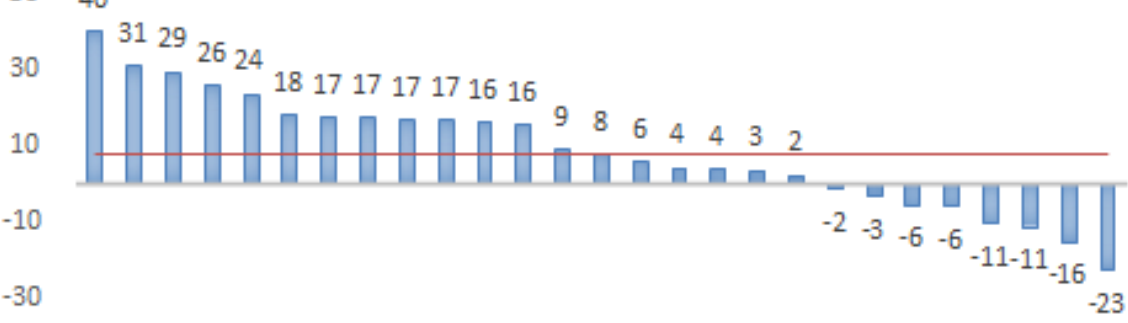

$$
\begin{aligned}
& -50
\end{aligned}
$$

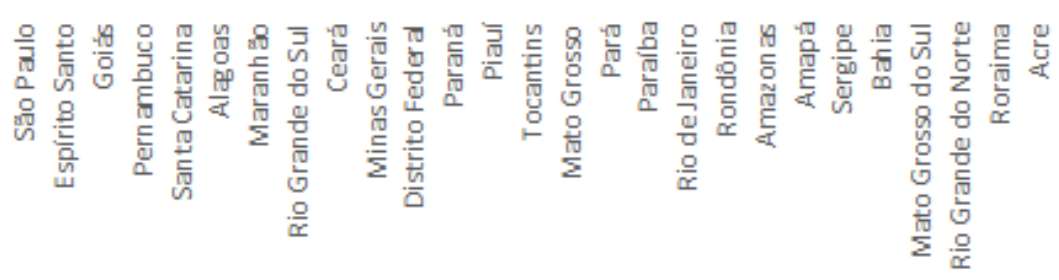

FONTE: Elaborado pelos autores

44\% dos Estados alcançaram pontuação acima da média (8 pontos), apesar disso, devido à baixa média global de transparência, fica claro que existem melhorias consideráveis a serem implementadas nos portais de transparência brasileiros para que se tornem efetivos em sua função de disseminar informações para a sociedade, bem como de reforçar e fomentar uma cultura de transparência no Brasil. Chama a atenção o fato de que 8 Estados (29,6\%), se encontram em nível comprometedor, o que evidencia uma falta de comprometimento desses Estados em fornecer informações à sociedade.

Dando prosseguimento à análise dos portais de transparência dos Estados brasileiros, apresenta-se a Figura 4, que representa o ranking dos estados em relação ao Conteúdo informacional. A melhor pontuação em relação à essa área de preocupação foi alcançada pelo Estado de Santa Catarina, com 46 pontos. Se por um lado a maioria dos Estados (74\%) alcançou nível adequado de transparência, fica evidente que $22 \%$ dos Estados se encontram em nível comprometedor, sendo que os Estados de Roraima e Acre apresentam um nível comprometedor preocupante, com uma avaliação negativa de 28 pontos. 25 Estados apresentam níveis de transparência semelhantes em relação à essa área, variando de 25 a 12 pontos e outros 4 Estados apresentam pontuação adequada, porém abaixo da média. Essa análise deixa claro que ainda existem diversas melhorias a serem implementadas nos portais de transparência dos Estados brasileiros. 


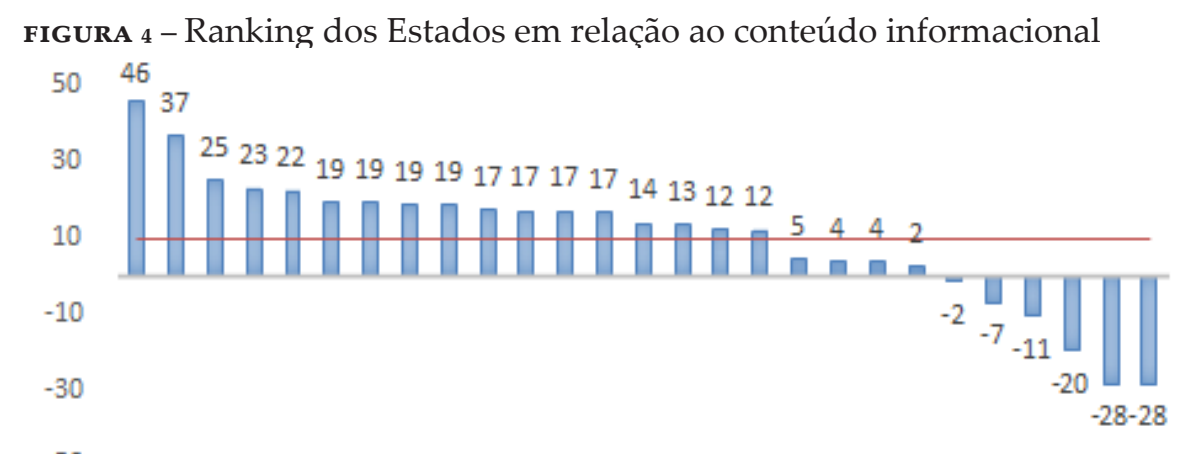

$-50$

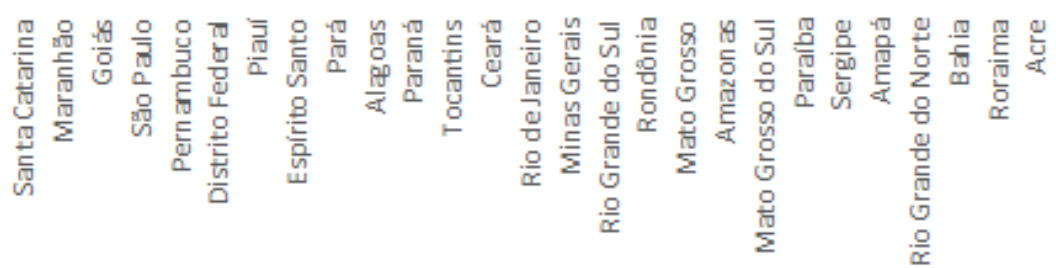

FONTE: Elaborado pelos autores

Destaca-se positivamente o PVF informação econômica e financeira, que alcançou uma média de 49 pontos, conforme apresentado na Figura 2. Nesse PVF todos os Estados alcançaram níveis adequados, além disso, 63\% dos Estados ficaram com um desempenho acima de 50 pontos, evidenciando a existência de uma preocupação com a disponibilização desse tipo de informação. Por outro lado, é crítica a situação dos portais de transparência dos Estados brasileiros em relação a disponibilização de informações sobre subvenções e ajudas públicas. A avaliação negativa de 44 pontos evidencia que não há preocupação por parte dos Estados em disponibilizar esse tipo de informação. Santa Catarina e Maranhão apresentam-se em nível Bom, ou seja, publicam os objetivos das subvenções, bem como os valores relacionados e os beneficiários dos pagamentos. Pará e Paraná apresentam as subvenções descrevendo seus objetivos, enquanto os demais Estados não publicam qualquer tipo de informação em relação a essa questão.

Em relação ao fomento à cultura de transparência, a literatura especializada aponta para a importância da utilização dos portais de transparência como um canal de comunicação com o governo e forma de disseminar e reforçar a cultura de transparência no setor público. Atualmente as redes sociais se constituem em ferramenta importante para comunicação entre governo e sociedade, bem como na disseminação de informações não somente sobre as ações do governo, mas também de informações sobre transparência, utilização de dados abertos, serviços aos cidadãos, entre outras questões, o que pode vir a gerar conhecimento sobre o tema aos cidadãos e incentivar a participação social nas decisões tomadas no setor público. Apesar disso, a menor taxa de substituição nessa área de preocupação (20\%), evidencia que na visão dos especialistas entrevistados essa atividade não se configura como prioridade para os portais de transparência. 
Ao analisarmos a Figura 5, fica evidente que não existe por parte dos Estados brasileiros interesse em utilizar os portais de transparência como uma ferramenta ao fomento da cultura de transparência. Apenas 2 Estados - Espírito Santo e São Paulo - alcançaram níveis adequados em relação a essa preocupação, porém, cada um deles se destacou em áreas diferentes, o Espírito Santo se destacou no uso de web 2.o e mídias sociais, enquanto São Paulo se destacou na disponibilização de dados abertos para reutilização. A média geral de 42 pontos negativos aponta para o fato de que grandes avanços ainda precisam ser feitos em relação a essa preocupação.

FIGURA 5 - Ranking dos Estados em relação ao fomento à cultura de transparência

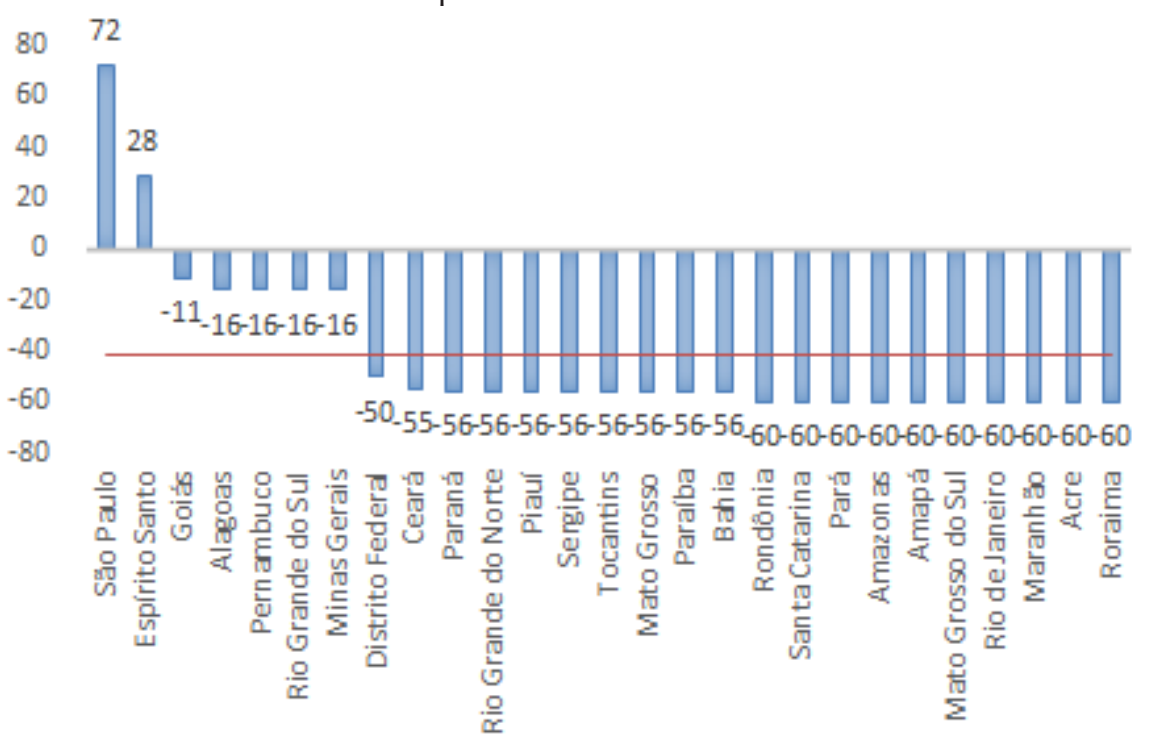

FONTE: Dados da pesquisa

Analisando em detalhe essa área de preocupação salienta-se que a melhor pontuação foi alcançada na divulgação de documentos de suporte ao cidadão (média de 13 pontos), justamente o PVF considerado menos importante, dada sua taxa de substituição de $25 \%$. Por outro lado, a questão da reutilização das informações, considerada a mais importante (taxa de $40 \%$ ) foi a que obteve o pior resultado médio, de 67 pontos negativos. A reutilização das informações diz respeito à disponibilização de dados abertos para uso e desenvolvimento de aplicações por parte de terceiros com base nesses dados.

O descritor proposto para esse critério se baseou nos dados prioritários a serem disponibilizados para a sociedade, conforme a cartilha técnica para publicação de dados abertos (BRASIL, 2011). O único Estado que atendeu plenamente a esse critério foi São Paulo, que alcançou nível de excelência (nível acima do nível Bom do descritor). Esse Estado disponibiliza dados organizados em catálogo e em formato estruturado, dados sobre suas competências e estrutura organizacional, repasses, transferências de recursos e despesas, informações sobre licitações e dados sobre acompanhamento de programas, ações, pro- 
jetos e obras, atendendo plenamente ao descritor. Além disso, divulga também uma série de outros dados de interesse público, relativos às suas ações na prestação de serviços aos cidadãos.

Os Estados que se encontraram em nível neutro disponibilizam informações em dados abertos, o que se configura como positivo. Apesar disso, esses dados prioritários, conforme a cartilha de publicação de dados abertos, não estão disponíveis. Em geral são disponibilizados dados sobre despesas e dados geo-referenciados sobre algumas atividades do governo - como por exemplo a localização de hospitais em mapas - porém, nenhum deles apresentou em formato aberto dados sobre as competências e estrutura organizacional dos Estados, o que impediu a possibilidade de alcançar níveis de transparência mais altos. Para o caso desses Estados, essa se configura como uma oportunidade de melhoria a ser implementada, nos demais casos (em nível comprometedor) é necessária toda a criação de uma área de dados abertos.

A última área de preocupação busca analisar os portais em relação à sua usabilidade. Em termos de importância, essa área de preocupação responde por $35 \%$ da avaliação global, envolvendo o acesso e utilização de dados, o suporte ao usuário e a autenticidade das informações. A Figura 6 apresenta o ranking dos Estados em relação a essa preocupação. Nessa área os Estados brasileiros alcançaram a melhor avaliação, com apenas um Estado - Mato Grosso do Sul - em nível comprometedor. Destacam-se Ceará e Goiás, que alcançaram 58 pontos.

FIGURA 6: Ranking dos Estados em relação à usabilidade dos portais

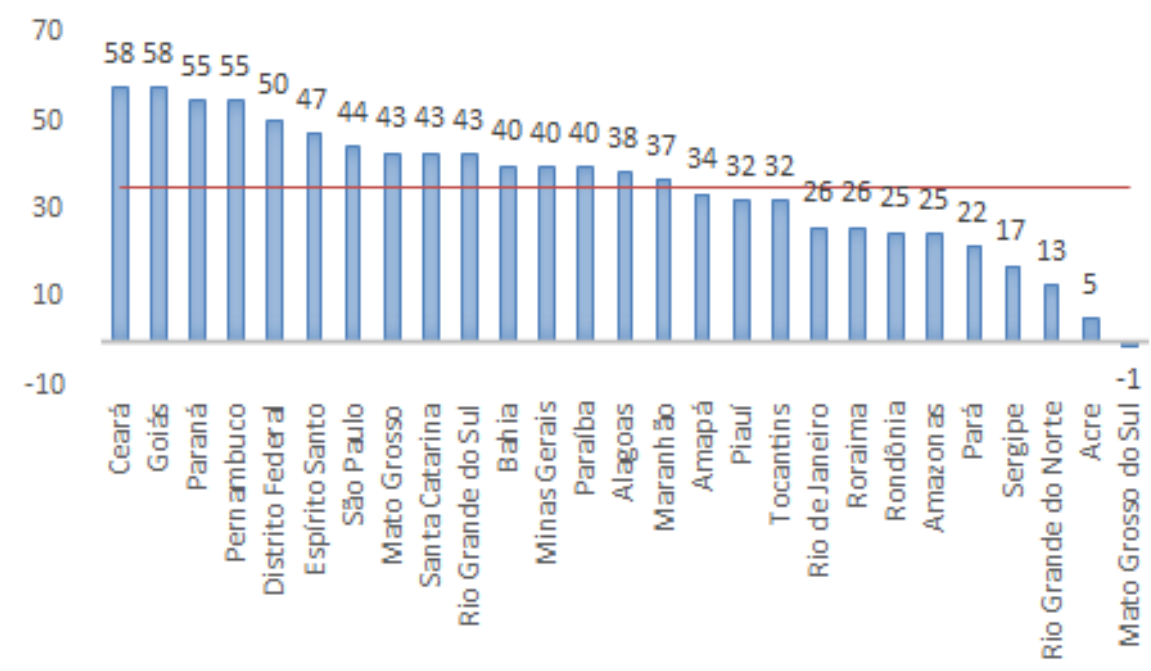

FONTE: Dados da pesquisa

Os Estados brasileiros alcançaram a melhor média de transparência nessa área de preocupação, com 35 pontos. O desvio-padrão baixo, de 15 pontos, evidencia que existe certa homogeneidade nas práticas de transparência relativas a essa questão. Analisando o desdobramento dessa área de preocupação em PVFs, verifica-se que o suporte ao usuário foi o PVF no qual os Estados foram melhor avaliados, alcançando 
média de 63 pontos. 33\% dos Estados alcançaram nível Bom, o que é positivo, uma vez que esse PVF se presta a facilitar a experiência do usuário no momento de acesso ao portal de transparência.

A questão mais importante em relação à usabilidade diz respeito ao acesso e utilização de dados, que responde por 50\% da avaliação global nessa área de preocupação. Aqui os Estados brasileiros alcançaram média adequada, de 32 pontos, sendo que apenas o Estado do Mato Grosso do Sul ficou em nível comprometedor (nível abaixo do nível Neutro).

O ponto crítico em relação à usabilidade do portal é a autenticidade das informações, nenhum dos Estados brasileiros fornece certificação digital dos documentos disponibilizados e permite sua revisão por meio de um número de certificado digital. Aqui se apresenta uma oportunidade de melhoria significativa haja vista que esse PVF já é diretamente relacionado a um descritor, que responde por $20 \%$ da avaliação global nessa área de preocupação.

Uma vez finalizada a apresentação e análise dos dados, a próxima seção busca tecer algumas considerações finais a respeito da aplicação do modelo de avaliação e dos resultados alcançados pelos portais de transparência analisados.

\section{CONSIDERAÇÕES FINAIS}

No âmbito das discussões sobre avaliação de transparência pública na Internet, o estudo objetivou realizar uma análise dos portais de transparência dos governos estaduais do Brasil. O modelo utilizado para análise, pelo fato de envolver questões sobre transparência que vão além do atendimento aos requisitos legais sobre transparência, permitiu uma análise mais ampla dessa questão, trazendo à tona resultados que demonstram ainda existir um longo caminho para que seja efetivamente implementada uma cultura de transparência no âmbito do setor público brasileiro.

Nos resultados da avaliação, em termos gerais, ficou evidente que os portais de transparência dos Estados brasileiros ainda precisam se aprimorar, tendo em vista que alcançaram somente 8 pontos na média da avaliação global, resultado este que veio a corroborar os resultados obtidos pelo estudo de Abdala e Torres (2016). Em termos da metodologia utilizada os portais se encontram em situação denominada 'adequada', ou seja, alcançaram uma média entre o nível Bom (100 pontos) e Neutro (o ponto). Apesar disso, a pontuação média obtida pelos Estados brasileiros acende um alerta em relação ao comprometimento de seus governos com a transparência da gestão pública, uma vez que se localizam muito mais próximos de um nível Neutro do que de um nível Bom.

Em relação ao conteúdo da informação, no que tange ao desempenho da gestão na prestação de serviços públicos, autores argumentam a favor da divulgação dessas informações (CERRILLO-I-MARTÍNEZ, 2012; CRUZ et al., 2012; GRIMMELIKHUIJSEN, 2012), porém, ao anali- 
sar o caso brasileiro os Estados que divulgam informações sobre saúde pública, educação e segurança são uma exceção. Além disso, nenhum Estado divulga informações sobre meio ambiente, questões consideradas importantes tanto na literatura quanto pelos especialistas entrevistados no decorrer da elaboração do modelo de avaliação utilizado neste estudo.

Tratando-se do fomento à cultura de transparência, no uso de web 2.o e mídias sociais a situação é crítica e vai de encontro ao que argumentam Bónson et al. (2012) e Cegarra-Navarro, Pachón e Cegarra (2012) sobre o uso dessas ferramentas no reforço à transparência no setor público e engajamento do cidadão. Apenas o Estado do Espírito Santo está presente em redes sociais, com perfis específicos sobre transparência em nível de excelência no Facebook e Twitter, bem como presença em outras redes sociais. Esses canais são utilizados para difundir informações sobre transparência, sobre as práticas utilizadas pelo Estado e também outras práticas consideradas por eles como interessantes para fomentar a transparência e participação social no Governo, o que o coloca em posição de benchmarking em relação a essa questão. O portal do Distrito Federal possui um canal no Youtube, que no momento da avaliação havia sido atualizado no mês anterior. Esse canal divulga vídeos explicativos, por exemplo, sobre como utilizar o portal de transparência e outros vídeos de interesse público.

Finalmente, em relação à usabilidade do portal, os Estados brasileiros se destacaram no que tange ao acesso e atualização dos dados, principalmente devido ao fato de que em relação à atualização das informações, em geral, os portais se utilizam de sistemas integrados, que "puxam" informações dos sistemas de gestão fiscal e as disponibilizam dados no dia de seu registro contábil, o que se configura como bastante positivo, tendo em vista que essas informações são dinâmicas, e se atualizam quase diariamente.

O Brasil é um país em desenvolvimento, de origem latina, em geral caracterizados por uma concepção legalista de administração pública, além disso, veio de um período de ditadura militar antes de entrar no atual período democrático em 1985 com o início da chamada Nova República. Assim, com base na discussão proposta por Ruijer e Meijer (2016) poder-se-ia inferir que teria, do ponto de vista do regime de transparência, um regime baseado em regras. Porém, apesar de possuir uma legislação sobre transparência bastante detalhada e desenvolvida pelo menos desde o ano 2000, com a promulgação da Lei de Responsabilidade Fiscal, até hoje, como fica evidente neste estudo, os portais de transparência dos Estados brasileiros sequer atendem completamente às exigências legais, o que é preocupante. Essa amplitude e antiguidade da legislação brasileira sobre transparência aponta para um regime baseado em regras, geralmente mais explícitas, detalhadas e prescritivas. Mais preocupante é o fato de que um regime baseado em regras pode ser considerado como um regime "direcionado pelo medo", ou seja, o cumprimento da regra viria de um receio por parte 
daqueles responsáveis, de sofrer sanções advindas por seu não-cumprimento, o que parece não estar ocorrendo no Brasil.

Assim, argumentamos que transparência, apesar de possuir um caráter legalista no que se refere aos instrumentos desenvolvidos para sua regulamentação e implementação, não se restringe ao caráter legal. O fato de existir legislação sobre transparência, não é fator que por si só torne determinado governo mais ou menos transparente, existe uma necessidade de internalização de cultura de transparência, que envolve tanto os agentes públicos responsáveis pela divulgação das informações, quanto a sociedade, que precisa se tornar um participante ativo no processo político. Como dito por Arellano-Gault e Lepore (2011) somente com a internalização desses valores será possível pensar em uma sociedade realmente transparente e assim, realizar as promessas inerentes ao acesso à informação e às políticas de transparência como elementos de uma governança democrática voltada ao cidadão.

Por fim, o processo de avaliação ocorreu em um determinado momento do tempo, assim, não foi possível por meio desta avaliação verificar a evolução dos portais em termos de melhoria das práticas de transparência, o que se configura como uma limitação do estudo. A aplicação continuada do modelo de avaliação poderá vir a trazer insights importantes sobre como os governos estaduais brasileiros vem gerenciando essa questão, sendo esta uma sugestão de pesquisa a ser desenvolvida. 


\section{REFERÊNCIAS}

ABDALA, P. R. Z; TORRES, C. M. S. de O. A

Transparência como Espetáculo: uma análise dos portais de transparência de estados brasileiros. Administração Pública e Gestão Social, v. 8, n. 3, p. 147-158, 2016.

ARELLANO-GAULT, D.; LEPORE, W. Transparency Reforms in the Public Sector: Beyond the New Economics of Organization. Organization Studies, v. 32, n. 8, p. 1029-1050, 2011.

BANA-E-COSTA, C. A.; CORTE, J.-M. De; VANSNICK, J.-C. M-Macbeth V. 1.1: manual do usuário, 2005.

BANA-E-COSTA, C. A.; VANSNICK, J.-C. Applications of the MACBETH approach in the framework of an additive aggregation model. Journal of multi-criteria decision analysis, v. 6, n. 2, p. 107-114, 1997.

BONSÓN, E. et al. Local e-government 2.o: Social media and corporate transparency in municipalities. Government Information Quarterly, University of Huelva, Plaza de la Merced, 11, 21071, Huelva, Spain, v. 29, n. 2, p. 123-132, 2012.

BRASIL. Constituição da República Federativa do Brasil: promulgada em 5 de Outubro de 1988, 1988.

BRASIL. Cartilha Técnica para Publicação de Dados Abertos, Ministério do Planejamento, Orçamento e Gestão, 2011.

CÁZARES, A. R.; CEJUDO, G. M. El acesso a la información gubernamental: análisis empírico de políticas de transparencia en cuatro países centroamericanos. Revista de Gestión Pública, v. II, n. 2, p. 335-381, 2013.

CEGARRA-NAVARRO, J.-G.; PACHÓN, J. R. C.; CEGARRA, J. L. M. E-government and citizen's engagement with local affairs through e-websites: The case of Spanish municipalities. International Journal of Information Management, v. 32, n. 5, p. 469-478, 2012.

CERRILLO-I-MARTÍNEZ, A. The Reuse of Public Sector Information in Europe and Its Impact on Transparency. European Law Journal, v. 18, n. 6, p. 770-792, 2012.

CRUZ, C. F. et al. Transparência da gestão pública municipal: um estudo a partir dos portais eletrônicos dos maiores municípios brasileiros. Revista de Administração Pública, v. 46, n. 1, p. 153-176, 2012.

CRUZ, N. F. Da et al. Measuring Local Government 
Transparency. Public Management Review, n. July, p. 1-28, 2015.

CUCCINIELLO, M. et al. Assessing public preferences and the level of transparency in government using an exploratory approach. Social Science

Computer Review, v. 33, n. 5, p. 1-16, 2014.

CUCCINIELLO, M.; PORUMBESCU, G. A.;

GRIMMELIKHUIJSEN, S. 25 years of transparency research: evidence and future directions. Public Administration Review, v. 77, n. 1, p. 32-44, 2017.

DINIZ, G. M. O estado da transparência digital de portais eletrônicos : um estudo nos municípios do Ceará. Revista do TCE-MG, v. 33, n. 4, p. 91-116, 2015.

ENSSLIN, L.; MONTBELLER-NETO, G.; NORONHA, S. M. Apoio à decisão: metodologias para estruturação de problemas e avaliação multicritério de alternativas. Florianópolis: Insular, 2001.

GAMA, J. R.; RODRIGUES, G. M. Transparência e acesso à informação: um estudo da demanda por informações contábeis nas universidades federais brasileiras. Transinformação, v. 28, n. 1, p. 47-57, 2016.

GODOY, A. S. Estudo de caso qualitativo. In: BANDEIRADE-MELO, R.; SILVA, A. B. (Eds.). Pesquisa qualitativa em estudos organizacionais: paradigmas, estratégias e métodos. São Paulo: Saraiva, 2006. p. 115-146.

GRIMMELIKHUIJSEN, S. Linking transparency, knowledge and citizen trust in government: An experiment. International Review of Administrative Sciences, v. 78, n. 1, p. 50-73, 2012.

GRIMMELIKHUIJSEN, S.; KASYMOVA, J. Not So Universal After All: Exploring the Meaning and Use of Government Transparency in Consensual and Majoritarian Democracies. Public Integrity, v. 17, n. 4, p. 389-407, 2015.

JORGE, S. M.; LOURENÇO, R. P.; ROLAS, H. A transparency ontology in the context of open government: a case derived from the portuguese context. In: XIX IRSPM CONFERENCE 2015, Birmingham, 30 March-1 april. Anais... Birmingham, 30 March-1 april

KISSLER, L.; HEIDEMANN, F. G. Governança pública: novo modelo regulatório para as relações entre Estado, mercado e sociedade? Revista de Administração Pública, v. 40, n. 3, p. 479-499, 2006. 
LOURENÇO, R. P. et al. Online Transparency for Accountability: One Assessing Model and two Applications. Electronic Journal of E-Government, v. 11, n. 2, p. 280-292, 2013.

LYRIO, M. V. L. Transparência da gestão pública em portais eletrônicos: uma análise no contexto do poder executivo dos governos subnacionais brasileiro e espanhol. Tese (Doutorado em Administração) Programa de Pós-Graduação em Administração. Universidade Federal de Santa Catarina, 2016.

LYRIO, M. V. L.; LUNKES, R. J.; TALIANI, E. T. C. Transparency in the contexts of Brazilian and Spanish governments: Proposal of a model for comparative analysis. In: XX IRSPM CONFERENCE 2016, 13-15 April, Hong Kong. Anais... 13-15 April, Hong Kong

LYRIO, M. V. L.; LUNKES, R. J.; TALIANI, E. T. C. Thirty Years of Studies on Transparency, Accountability, and Corruption in the Public Sector: The State of the Art and Opportunities for Future Research. Public Integrity, p. 1-22, 2018.

MEIJER, A. J. Understanding modern transparency. International Review of Administrative Sciences, v. 75, n. 2, p. 255-269, 2009.

MEIJER, A. J. Government Transparency in Historical Perspective: From the Ancient Regime to Open Data in The Netherlands. International Journal of Public Administration, v. 38, n. 3, p. 189-199, 2015.

MEIJER, A. J.; HART, P.; WORTHY, B. Assessing Government Transparency: An Interpretive Framework. Administration \& Society, p. 1-26, 2015.

NUNES, G. S. de F. Avaliação da transparência pública à luz da legislação brasileira: um estudo nos municípios da Região Sul do Brasil. 2013. Universidade Federal de Santa Catarina, 2013.

PEDERSEN, A. R.; SEHESTED, K.; SØRENSEN, E.

Emerging theoretical understanding of pluricentric coordination in public governance. The American Review of Public Administration, v. 41, n. 4, p. 375-394, 2010.

RAUPP, F. M.; PINHO, J. A. G. De. Os vereadores prestam contas em portais eletrônicos? Um estudo comparativo entre municípios do Estado da Bahia e de Santa Catarina. Administração Pública e Gestão Social, v. 5, n. 3, p. 89-97, 2013.

ROBICHAU, R. W. The mosaic of governance: creating a picture with definitions, theories and debates. Policy Studies Journal, v. 39, n. S1, p. 113-131, 2011. 
RUIJER, E.; MEIJER, A. J. National Transparency Regimes: Rules or Principles? A Comparative Analysis of the United States and The Netherlands. International Journal of Public Administration, v. 0692, n. January, p. 1-14, 2016.

SAUERBRONN, F. F. Governança pública em saúde pósreforma gerencial no Brasil: Reconciliando perspectivas para uma análise multinível. Administração Pública e Gestão Social, v. 9, n. 3, p. 148-158, 2017.

SILVA, G. C. Da; NASCIMENTO, G. C. R. Do; FERREIRA, C. D. Transparência na prestação de contas da administração pública municipal na Internet: um estudo de caso no Estado de Goiás. In: CONGRESSO UFSC DE CONTROLADORIA E FINANÇAS 2014, 19 a 21 de Maio, Florinanópolis. Anais... 19 a 21 de Maio, Florinanópolis: Universidade Federal de Santa Catarina, 2014.

SOUZA, F. J. V. De et al. Índice de transparência municipal: um estudo nos municípios mais populosos do Rio Grande do Norte. Revista de Gestão, Finanças e Contabilidade, v. 3, n. 3, p. 94-113, 2013.

STAROSCKY, E. A. et al. A transparência dos portais das prefeituras em municípios catarinenses sob a perspectiva da legislação brasileira. REUNA, v. 19, n. 1, p. 29-52, 2014.

STAROSCKY, E. A. et al. An Analysis on the Web Portals of the Municipalities Comprising the Regional Development Bureau of Joinville (SC), Based on a Multicriteria Decisionmaking Model. Public Administration Research, v. 4, n. 1, 2015.

TORFING, J.; SØRENSEN, E.; FOTEL, T. Democratic anchorage of infrastructural governance networks: the case of the Femern Belt Forum. Planning Theory, v. 8, n. 3, p. 282-308, 2009. 